\title{
Espectáculo, teatro y comitencia política en la(s) Italia(s) del Renacimiento
}

\section{Artículo científico}

Nora Sforza ${ }^{1}$

FFyL - UBA

Material original autorizado para su primera publicación en el Journal de Ciencias Sociales, Revista Académica de la Facultad de Ciencias Sociales de la Universidad de Palermo.

Recibido: 13-3-2016

Aceptado: $27-4-2016$

Resumen: Este artículo estudia las intrincadas relaciones entre gobernantes, autores de obras de teatro y realizadores de entretenimientos en algunas áreas de la multicéntrica Italia entre fines del siglo XV y las primeras décadas del XVI. El objetivo apunta a observar similitudes y diferencias entre los medios por los cuales la corte de Ferrara y la República oligárquica de Venecia ofrecían variados espectáculos y festivales en aquel tiempo.

Los diferentes tipos y modos de entretenimientos comunes en este período son también analizados. Una amplia variedad de ejemplos paradigmáticos lo constituyen las obras de Ariosto y Belco, que fueron incluidas en nuestro estudio para comprender la complejidad de estos procesos.

Palabras clave: Renacimiento italiano - espectáculos - comitencia - comedia - Ariosto - Ruzante

Abstract: This article studies the intricate relationships between principals, play writers and makers of entertainments in some areas of the multicentric Italy, between the end of the XV century and the early decades of the XVI. The aim is to observe and point out similarities and differences between the ways in which the court of Ferrara and the oligarchic Republic of Venice offered varied performances and festivals at that time.

1 Doctora en Letras por la Universidad de Buenos Aires, Magíster en Historia por FLACSO (Facultad Latinoamericana en Ciencias Sociales) y Licenciada en Lengua y Cultura Italianas por la Universidad de Pisa, Italia. Profesora Especialista en Teatro del Renacimiento italiano y en temas de Italianística. Ha curado, entre otras, la edición de la Ficción completa de Nicolás MAQUIAVELO, Premio "Teatro del Mundo 2011" en el rubro “Traducción” (Colihue Clásica, 2010). Correo electrónico: info@norasforza.com.ar 
The different types and ways of entertainments common in that period are also analysed. A variety of paradigmatic examples taken from Ariosto's and Belco's plays are included in order to understand the complexity of the whole process.

Keywords: Italian Renaissance - performances - principals - commedy - Ariosto - Ruzante

\section{A modo de Introducción}

A lo largo de los siglos, la cultura italiana ha sido caracterizada fundamentalmente por un pluricentrismo que la ha atravesado y construido con inusitada fuerza, para bien y para mal. Y es probable que el Renacimiento (para no decir, claro está, los múltiples Renacimientos de los que podríamos hablar en esta sede) haya sido uno de los momentos de su historia en que esta característica -casi su razón fundantefue más visible. En este período, sin embargo, encontramos algunos elementos que pueden ser repetidamente observados a lo largo y a lo ancho de toda la península, dividida entonces en múltiples estados de origen y condición bien diversa, tantas veces enfrentados entre sí y con las potencias extranjeras. Entre estos elementos, la comitencia política se nos revela como un factor determinante a la hora de construir, legitimar, sostener, prolongar o consolidar el poder, estuviese éste ligado al mundo de las cortes (seculares o eclesiásticas) o bien al de los gobiernos republicanos que con enormes diferencias entre sí, también convivían en este complejo universo.

Ahora bien, dentro de este contexto variopinto y de esta cultura profundamente escenográfica, el teatro y las que podríamos definir como "formas espectaculares" fueron factores determinantes en la construcción de las diversas formas del poder político que caracterizaron el período. Así, observamos entonces que la idea de espectáculo es verdaderamente amplia y plural, pues se refiere no solamente a las representaciones teatrales stricto sensu, sino también a cualquier tipo de fiesta, vg. entradas triunfales, banquetes, triunfos, torneos, fiestas acuáticas, fuegos artificiales. Estas formas festivas eran cuidadosamente preparadas por una verdadera pléyade de personas encargadas exclusivamente de estas tareas, en ocasiones tan disímiles como podían ser los matrimonios, los nacimientos, las llegadas de embajadas y de huéspedes ilustres, los triunfos militares y aún los funerales. Es así como vemos que a lo largo del siglo XV y principios del XVI, la dimensión colectiva e interclasista de la otrora tradicional fiesta cívica dejará progresivamente espacio al esplendor de un nuevo tipo de fiesta, cada vez más sofisticada, novedosa y costosa, la cual, en muchos casos, modificaba sensiblemente el rostro de la ciudad mientras 
duraba la misma. En este sentido, reconocidos casos como el de Leonardo da Vinci, familiare de Ludovico el Moro entre 1482 y 1499, nos ayudan a comprender la importancia y la centralidad de la cuestión. Sin embargo, en este trabajo nos detendremos en dos universos que consideramos paradigmáticos, a saber, la República de Venecia por una parte y, por la otra, las cortes de Ferrara (y tangencialmente y por cuestiones ligadas a un universo familiar compartido, las de Mantua y de Milán) ${ }^{2}$, en el periodo que va desde 1480 (momento de los primeros y sistemáticos intentos de vulgarización de comedias de impronta latina) hasta 1542 (año de la muerte de Angelo Beolco y prolegómeno de lo que podríamos considerar "el fin de la fiesta" renacentista que impondrá la cultura tridentina, profundamente ligada a fuertes programas de disciplinamiento y coherción individuales y colectivos).

Sin duda, "el teatro del Renacimiento, en su dimensión culta, ha encontrado su más amplia y significante unidad formalizante en la fiesta." ${ }^{3}$ Si centramos entonces nuestra atención en la "fiesta teatral" en sentido amplio deberemos recordar que, evidentemente, cada vez que hablamos de representación teatral -y sobre todo si tenemos en cuenta que durante el período que estamos estudiando aproximadamente el noventa por ciento de las representaciones estaba relacionado con la puesta en escena de comedias-, veremos que existe una necesidad por parte de los anfitriones -ligados fundamentalmente al sistema cortesano- de demostrar la propia magnificencia al realizar esas performances sin considerar los enormes gastos ${ }^{4}$ que todo este movimiento requería. Dentro de este contexto general, la notable preponderancia de la comedia sobre otras formas teatrales es explicada por Fabrizio Cruciani (1972) quien considera que

el público se encuentra, en la fiesta, en la posición alejada y tranquila de quien está por encima, casi una divinidad frente al agitarse humano, consolidado y seguro en su protección ideal (una sociedad estática y ordenada): puede ver todo porque nada lo llama a actuar. Lo que podría quizás [...] explicar la preponderancia de la comedia y la dificultad de proponer la tragedia. ${ }^{5}$

Así, pues, "la escena, la fiesta teatral en general, se transforman durante el siglo XVI en uno de los modos privilegiados de los señores para mostrar y confirmar el propio poder y para mantener, al mismo tiempo, el equilibrio que comienza ya a delinearse siempre con mayor claridad. Desde la mitad del siglo XV

\footnotetext{
${ }^{2}$ Recordemos que el duque de Ferrara, Hércules I casaría a sus hijas Isabel (1474-1539) y Beatriz (1475-1497), frutos de su matrimonio con Elenora de Aragón, respectivamente con Francisco II Gonzaga, duque de Mantua y Ludovico Sforza, el Moro, duque de Milán.

${ }^{3}$ Cruciani, Fabrizio, "Il teatro e la festa." En Cruciani, Fabrizio e Seragnoli, Daniele (comp.), Il teatro italiano del Rinascimento (Cruciani, 1987, p. 31).

${ }^{4}$ Una nueva línea de investigación se hallaría justamente en el estudio de esos pormenorizados gastos que figuran en los libros contables de las ciudades nombradas arriba. En este sentido, es iluminante como punto de partida de una reflexión en propósito el reciente estudio de Isabella Palumbo Fossati Casa, Dentro le case. Abitare a Venezia nel Cinquecento (2013), para pensar estas cuestiones en clave de microhistoria.

${ }^{5}$ Cruciani, Fabrizio, "Il teatro e la festa." En Cruciani, Fabrizio e Seragnoli, Daniele (comp.), II teatro italiano..., (Cruciani, 1987, p. 38)
} 
se enciende entre las cortes italianas una gran rivalidad que imprime un incremento ulterior a las fiestas públicas utilizadas por los poderosos como prueba de su prestigio, tanto para fines internos como para fines externos [...] con particulares funciones de propaganda" ${ }^{6}$ en sentido moderno.

Como es dable observar, quienes impulsaban este sistema de comitencia tenían así la oportunidad de ostentar su prodigalidad al tiempo que buscaban establecer ciertas diferencias, según fuesen los destinatarios de los antedichos espectáculos. En términos muy generales, podríamos hablar grosso modo de dos grandes tipos de fiesta espectacular, a saber:

1. aquellos espectáculos reservados exclusivamente a quienes hoy podríamos definir como "grupo de pares" del señor (en el caso de las señorías) o de los miembros del Consejo de los Diez (en el caso de la República de Venecia), o a aquellas personas con las que estos necesariamente debían construir cierto tipo de relaciones y que, por lo tanto, eran invitadas por los señores o por el Dux veneciano. Lo interesante del caso es que tales obras generalmente eran interpretadas por los mismos miembros de esta élite dirigente en el interior de sus habitaciones, ocasionalmente preparadas para $\operatorname{tal} \mathrm{fin}^{7}$, en una época en la que verdaderamente no existía la idea de la privacy tal cual la entendemos hoy. El trabajo mancomunado de este grupo de aficionados con actores protoprofesionales (en tanto y en cuanto estos, por regla general, se encontraban vinculados a estas élites dirigentes como "familiares" de las mismas, en una relación desigual y de subordinación) se nos presenta, pues, como un elemento esencial en esta construcción del espectáculo en los albores de la Modernidad clásica.

2. los espectáculos dedicados al pueblo -entendido éste en sentido amplio- cuya única participación era la de ser simple observador "ya que no le era dado intervenir activamente en la presentación de los espectáculos ofrecidos. Estos eran entonces una ocasión fundamental para que el mismo señor o los miembros del gobierno de Venecia, según el caso, pudieran dar muestras de su evergetismo a través de este verdadero programa de propaganda en sentido moderno, al tiempo que se buscaba renovar una suerte de Nachleben de los Antiguos que también habían sostenido este tipo de programa evergético, de panem et circenses, según la precisa definición que hiciera Décimo Junio Juvenal (Aquino, 60 - Roma, 128) en su Sátira

\footnotetext{
${ }^{6}$ Attolini, Giovanni, Teatro e spettacolo nel Rinascimento. (Attolini, 1997, p. 6).

${ }^{7}$ La idea de lo efímero de estos espectáculos se hace presente también aquí pues, como vemos, a pesar de la importancia que se les atribuía desde el punto de vista de la organización y de los gastos estipulados para su preparación, no habrá, hasta finales del período que estamos estudiando, la idea de una sala teatral construida ad hoc. En cierto sentido, la experiencia de la sala de madera, con palco y escenas fijas, construida en el castillo estense de Ferrara y conocida como el "teatro de Ariosto", destruida por un incendio en 1532, quedará como un experimento aislado hasta bien entrado el siglo y aún más durante la primera mitad del próximo, cuando las salas teatrales fijas comiencen a irrumpir en el tejido urbano de varias ciudades italianas tales como Vicenza, Sabbioneta, Venecia o Parma, entre otras).
} 
$X$ (vv. 77-81) . De este modo "la motivación política de las fiestas y de los espectáculos se hace cada vez más explícita: en las cortes laicas como en las eclesiásticas, el problema no es ya sólo el de divertir al pueblo, sino el de asociarlo, aparentemente, al ejercicio del poder. ¿De qué manera? Convenciéndolo de su rol de súbdito, aturdiéndolo con la magnificencia” ${ }^{8}$ de una vida a la que jamás podrá acceder, pero además alejándolo del tiempo ordinario e insertándolo en un tiempo verdaderamente inconmensurable, o sea el tiempo ideal de la celebración. Esta suerte de regalo que el señor ofrecía a sus gobernados -verdadero instrumentum regni- tenía todas las características materiales de lo efímero pues las escenografías de cada uno de estos espectáculos, si bien eran pensadas con extremo cuidado por parte de los organizadores, debían ser cambiadas y reelaboradas una y otra vez dado que también la capacidad de innovación permanente formaba parte de este juego de afirmación del poder, ${ }^{9}$ que iría complejizándose cada vez más, hasta llegar a las inverosímiles y artificiosas creaciones típicas del teatro barroco.

Como puede observarse "la política no estaba hecha sólo de paces o de guerras ganadas o perdidas sino también y sobre todo de cultura y de arte, mediante los cuales el señor se ponía en el centro de la civilización y ejercitaba una indiscutida hegemonía," ${ }^{10}$ al tiempo que utilizaba estos elementos como medio (y fin) para su propia legitimación en el interior de un poder cuyo origen no siempre era completamente lícito. En realidad, este sistema permitirá en el período que estamos estudiando, el progresivo afirmarse de la cultura de una élite que se muestra solamente en los ambientes que suele frecuentar, que son los mismos en los que pone en ejercicio su poder político, mientras la mayoría de la población continúa siendo considerada como un mero objeto que permanece o asiste como tal a las actividades que el grupo hegemónico impone sobre ella. "La fiesta, el teatro, se insertan en este punto justamente para disimular una realidad tan contradictoria, [ellas] se transforman en un instrumento del poder para enmascarar y especialmente para tratar de hacer olvidar las diferencias sociales, anulando aquélla que se podría definir como la agresividad histórica de los dominados en el imaginario, en una liberación puramente lúdica." ${ }^{11}$ Es clara entonces la finalidad política de las fiestas, en tanto y en cuanto los gobernantes se esfuerzan en ofrecer una imagen lo más unitaria posible, al menos en el artificio del juego, ${ }^{12}$ juego en el que se entremezclan permanentemente espectáculo y poder. Por otra parte será necesario recordar aquí que en la época que estamos analizando generalmente "el ducado ya es un estado consolidado en sus instituciones y, no obstante algún acto conspirativo rápidamente reprimido, ejerce un rígido control sobre la economía y

\footnotetext{
${ }^{8}$ Attolini, Giovanni, Teatro e spettacolo...Op. Cit. (Attolini, 1997, p. 35).

${ }^{9}$ Cfr. Strong, Roy, Arte y poder. (Strong, 1984, p. 36).

${ }^{10}$ Vaini, Mario, "Economia e società a Mantova dal Trecento al Cinquecento." En Prosperi, Adriano (a cura di), La corte e il "cortigiano". Un modello europeo, Vol. II. (Vaini, 1980, p. 56).

${ }^{11}$ Attolini, Giovanni, Teatro e spettacolo... Op. Cit., p. 10.

12 Ibidem, Op. Cit., p. 24.
} 
sobre la política, logrando fuertes relaciones con la nobleza que está netamente dividida del resto de la población y afirmando su propio primado con una intensa vida cultural." ${ }^{13}$

\section{Espacios de representación}

Ahora bien: los espectáculos a los que hacemos aquí referencia eran pensados generalmente para ser representados en el patio de los palacios ducales, mientras que en el caso específico de la ciudad de Venecia, en sí verdadero teatro all'aperto, la misma escenografía ciudadana ofrecía el marco adecuado para la realización de dichos espectáculos. En este sentido es por lo tanto fundamental tener en cuenta que la ciudad se transforma aquí en el eje de todas las actividades no sólo económicas, políticas o administrativas sino también y sobre todo culturales. Evidentemente, la cuestión de los loci donde se desarrolla esta suerte de política cultural era fundamental pues, si por un lado podemos a veces observar la presencia de efímeros- espacios creados ex-novo en los salones internos de la vivienda señorial, los cuales -como hemos visto- eran permanentemente modificados (casi como los modernos SUM de los edificios actuales) para que pudiese llevarse a cabo la puesta en escena de obras con las que se agasajaba a aquellos con los que el señor establecía cierto tipo de relación, por otra parte la decoración de los patios y, en términos generales de otros espacios abiertos del castillo o palacio del señor, se realizaba pensando en una concurrencia mucho más numerosa aunque al mismo tiempo no "calificada", como en cambio sucedía en el primer caso. En este sentido, resulta muy interesante recordar, a modo de ejemplo, las famosas cartas que Isabel d' Este dirigiera desde Ferrara a su esposo, Francisco Gonzaga, a principios de 1502, en ocasión de las grandes fiestas organizadas en Ferrara para las bodas del hijo del duque, Alfonso, con Lucrecia Borgia. Isabel escribía entonces

El señor mi padre me condujo para ver la sala donde se representarán las Comedias, la cual tiene ciento cuarenta y seis pies de largo y cuarenta y seis de ancho. Del lado de la plaza están construidas las graderías, y así las cabeceras, que son trece, con dos parapetos para dividir a las mujeres de los hombres: las mujeres estarán en el medio y los hombres de cada lado; el techo y las graderías están recubiertos de paños verdes, rojos y blancos. Del otro lado, o sea frente a las graderías, se ha construido un muro de madera, adornado como lo está el muro de la ciudad, tan alto como un hombre. [...] Se estima que cabrán cerca de cinco mil personas; pero primero los extranjeros ocuparán las gradas; si quedase lugar, será para los gentilhombres ferrareses. En el techo de la sala hay cinco escudos: el papal en el medio, a la derecha, el del rey de Francia, a la izquierda, el ducal estense, a la derecha el de los Borgia y los Estensi juntos, a la izquierda el antiguo escudo de la casa, o sea el águila mitad negra y mitad blanca: no he visto nada más digno de noticia. Las barras del ingreso son también de madera desnuda: no sé si las cubrirán más adelante. De todo lo que veré en el día, haré partícipe a V.E.

\footnotetext{
${ }^{13}$ Ibidem, Op. Cit., p. 32.
} 
El pasaje citado precedentemente es muy importante pues no sólo relata con precisión las características "físicas" de los espacios de la celebración sino que también muestra los modos "jerárquicos" en los que dichos espacios serán ocupados.

Finalmente, éste es el sentido con el que, siempre en la misma carta, Isabel necesita dar testimonio de cada una de las novedades y de los fastos que necesariamente debían formar parte del orden del espectáculo:

muestra de todos los vestidos que entran en cinco comedias para que se supiera que los vestidos fueran hechos a tal fin, y que los de una Comedia no sirvieran para las otras. Son en total ciento diez, entre masculinos y femeninos; los hábitos son de cendal ${ }^{14}$, y algún otro de camelote $e^{15}$ para la moresca. $^{1617}$

Pero finalmente, ¿qué entendemos por fiesta de corte y de pueblo, cada vez que nos referimos a determinados tipos de festejos en la Italia del primer Renacimiento? En realidad, los patios de los palacios, los grandes salones y muchas veces las plazas ciudadanas frente a las residencias de los nobles se transformaban, como estamos viendo, en fastuosos teatros provisorios. ${ }^{18}$ Por supuesto no debemos pensar en espectáculos teatrales de características similares a los actuales: se trataba más bien de una suerte de grandes combinaciones eclécticas en las cuales podían encontrarse mezclados sin solución de continuidad bailes y banquetes junto con espectáculos teatrales en sentido moderno, en los que el texto tuviera un protagonismo mayor. Finalizados estos, se utilizaba el mismo espacio de la platea liberada de las sillas y se daba inicio a la última fase de los bailes y de los almuerzos o cenas que eran sentidos, ellos mismos, como verdaderos espectáculos y cuya preparación preliminar requería el arduo trabajo de un verdadero ejército de personas a lo largo de semanas y aun meses. ${ }^{19}$ Ya desde el último cuarto del siglo XV, durante los

\footnotetext{
${ }^{14}$ El cendal es un tejido de seda fina.

${ }^{15}$ El camelote es un paño de lana muy suave.

${ }^{16}$ La moresca es una danza originaria del Medioevo, seguida por bailarines vestidos de guerreros, cuyo objetivo era recordar los combates entre cristianos y moros, y justamente de allí toma su nombre. Estas exhibiciones se transformarán durante el siglo XVI en verdaderas acciones coreográficas, puntillosamente preparadas.

17 "... mostra di tutti i vestimenti che entrano in cinque commedie a fine che si conoscesse che li vestimenti fussero facti a posta, et che quelli de una Comedia non havesseno ad servir le altre. Sono in tutto cento diece, fra homini e donne; li habiti sono de cendale, et qualche uno di zambellotto a la moresca." Fragmento de la carta de Isabel d'Este a Francesco Gonzaga del 3 de febrero de 1502, cit. en D'Ancona, A., Origini del teatro italiano. Vol II. (D'Ancona, 1891, p. 384). Todas las traducciones contenidas en el presente artículo nos pertenecen.

${ }^{18}$ Insistimos en el hecho de que los primeros teatros all'antica concebidos desde su origen para cumplir sólo la función de espacio de representaciones teatrales, surgen sólo en la segunda mitad del siglo XVI. En este sentido, recordemos los ejemplos del teatro "Olímpico" (así llamado por haber sido encargado por los miembros de la "Academia Olímpica") de Andrea Palladio en Vicenza (1585); el de Vincenzo Scamozzi en Sabbioneta (Mantua) (1590) y el Farnese de Giovanni Battista Aleotti llamado l'Argenta en Parma (1618-19). Los tres teatros continúan elaborando espectáculos todavía hoy.

${ }^{19}$ En este sentido vale la pena recordar la importante cantidad de escritos que en torno al tema de la presentación de los banquetes ha llegado hasta nosotros. Así por ejemplo nos ha sido posible consultar el tratado de Cristoforo da Messisbugo (o Messi Sbugo), Banchetti composizioni di vivande e apparecchio generale, publicado póstumo en Venecia en 1549. Messisbugo (¿Flandes? - Ferrara, 1548) fue un famoso cocinero y apparatore (vale decir organizador) de fiestas en la corte ferraresa de Alfonso I d'Este. Gracias a él nos enteramos de cómo, entre plato y plato, podían ser representadas piezas teatrales, fundamentalmente cómicas.
} 
banquetes $^{20}$, los comensales -quienes, según parece, necesitaban gozar de un entretenimiento permanente que evitase desmanes- ${ }^{21}$ eran también entretenidos con muy variadas representaciones acompañadas por cantos y danzas, generalmente de tema mitológico y bucólico, cuya continuidad dramática era interrumpida por intermedios de argumentos dispares, los cuales, a su vez, en un primer momento se realizaban como danzas, generalmente morescas y más tarde combates (conocidos generalmente como abbattimenti) ${ }^{22} \mathrm{y}$, por lo menos durante el período que estamos analizando, eran presentados frente a la misma perspectiva escenográfica de la comedia, pues todavía no se habían difundido los cambios a escena abierta. ${ }^{23}$ Según algunos críticos, de aquí podría haber surgido inclusive el modelo del drama pastoral y podríamos recordar con justicia en esta sede al Orfeo de Poliziano, que también habría sido estrenado precisamente durante un banquete: aquél ofrecido en Mantua por el cardenal Gonzaga a sus hermanos el martes gordo de $1480 .^{24}$

Ahora bien, si consideramos las ciudades objeto de nuestra investigación durante el periodo ya mencionado, ciertamente la corte Estense en Ferrara es la que se demostrará como la más original e innovativa en relación con la preparación de las puestas en escena de los espectáculos que ofrecía. En términos generales, dicha corte dará gran importancia al factor estético y, como hemos ya visto en el fragmento de la carta de Isabel d'Este a su marido citada supra, se consideraba fundamental que, por ejemplo, no se repitieran los trajes que serían utilizados y que para cada representación toda la

\footnotetext{
${ }^{20}$ Elvira Garbero Zorzi refiere que “las imágenes de los banquetes recurren con frecuencia en la pintura del ‘ 400 y del ‘500 pero, en dicha época, es raro el testimonio figurativo de las acciones escénicas que eran representadas o de los personajes que las actuaban." Vide "La festa cerimoniale del Rinascimento. L'ingresso trionfale e il banchetto d'onore." En Garbero Zorzi, Elvira e Romagnoli, Sergio (comps.), Scene e figure del teatro italiano (Zorzi, 1985, p.74).

${ }^{21}$ En este sentido, es imposible olvidar el pionero ensayo de Norbert Elias, El proceso de la civilización. Investigaciones sociogenéticas y psicogenéticas (1939), en el que el sociólogo alemán estudia la evolución del comportamiento, a partir del análisis de un corpus de manuales de comportamiento desde el siglo XIII hasta el siglo XVII, los cuales consignan la progresiva transformación del comportamiento y la afirmación del self-control moderno.

${ }^{22}$ El abbattimento se origina en la moresca del siglo XV y puede ser visto como una especie de combate-ballet, ejecutado por grupos vestidos con armaduras. Es probable que el más exitoso de todos haya sido el Combattimento di Tancredi e Clorinda, cuyo texto fuera tomado por Claudio Monteverdi de un episodio de la Gerusalemme Liberata de Torquato Tasso y cuya primera representación tuviera lugar en la residencia veneciana de la noble familia de los Mocenigo, en 1624.

${ }^{23}$ "La función del intermedio durante el transcurso de la comedia es simplemente la de esconder al público la rotación de la escena. Si, en una primera fase él desarrolla la tarea de una máquina-telón, más tarde se apropia del descubrimiento y de pretexto se transforma en protagonista." En Attolini, Giovanni, op. cit., p. 129. De todas maneras es importante recordar aquí que los intermedios de la época que estamos analizando eran interpretados por muchachos y muchachas que mostraban una fiesta campestre, entre ninfas, pastores y campesinos. Sólo excepcionalmente entraban en escena las divinidades olímpicas o las figuras alegóricas que serán tan características durante el siglo XVII. Cfr. Molinari, Cesare, Storia del teatro. Bari, Laterza, 1996, pp. 79-80. Por otra parte, es importante recordar que por lo menos durante el período que estamos analizando, los intermedios eran presentados frente a la misma perspectiva escenográfica de la comedia, pues todavía no se habían difundido los cambios a escena abierta, dado que el uso del telón en sentido moderno prevalecerá recién a partir de la primera mitad del siglo XIX. En efecto, deberemos esperar las representaciones parisinas de Guglielmo Tell de Giacchino Rossini, en 1839, para que se haga habitual el uso romántico de abrir y cerrar el telón entre acto y acto. En los siglos anteriores, en cambio, el telón era generalmente pintado con alegorías que, cuando estaba cerrado, permitían que se integrara al resto de la sala como formando parte de un mismo gran cuadro. Vide Cruciani, Fabrizio, Lo spazio del teatro (Cruciani, 1992. p. 15).

${ }^{24}$ En realidad, si pensamos en estos intermedios de las danzas observaremos verdaderas representaciones, muchas veces unidas las unas a las otras por un mismo hilo conductor, acompañadas por un comentario musical, danzadas y cantadas. En realidad este género se transformaría con el correr del tiempo en lo que luego serían llamados los intermezzi, espectáculos coreográficos mixtos de música, canto y danza que contenían in nuce muchos de los elementos que caracterizarían posteriormente al melodramma del siglo XVII y que serán insertados entre un acto y el otro de la comedia, con el argumento de la cual, por regla general no tenían nada que ver.
} 
construcción visual fuera efectivamente nueva. Responsable de la preparación de la puesta en escena y a veces (como en los casos de Ariosto o Ruzante) inclusive de la actuación era, generalmente, un literato, autor del texto que se iba a representar. Es este el motivo por el que lo hemos dado en Ilamar autorrepresentador o, si se quiere, con término más reciente, teatrista en sentido amplio. Sin embargo, es esencial tener en cuenta que en este tiempo toda su actividad estaba supervisada por el mismo comitente, quien, como hemos visto, podía no fijarse en gastos, siempre y cuando quedase conforme con los resultados obtenidos. En cuanto a las escenas y a los vestidos, de esto se ocupaba el pintor de la corte. ${ }^{25}$ Llegados a este punto es importante considerar que "el público no quería asistir tan sólo a reconstrucciones históricas; quería más bien satisfacer a su propio ojo. Por esta razón [...] el vestido asumió una gran importancia desde el punto de vista teatral en cuanto por primera vez fue creado para ser encuadrado en un único contexto pictórico con la escena, creando con ella una única visión de arte; cosa facilitada por el hecho de que generalmente el artista que creaba la escena era el mismo que había diseñado los vestidos." ${ }^{26}$ Ya lo diría el espectador Jano Pencaro en su carta a Isabel d'Este del 9 de febrero de 1499, donde explicaba que sobre el escenario donde se representaba el Eunuco de Terencio desfilaban

todos aquellos que tenían que representar todas las comedias... vestidos todos con vestidos nuevos, hechos para la ocasión, quien de raso, quien de camelote... quien de cendal, quien [con] paños y quien [con] sutilísimas telas, [quien con] hábitos formados según diversas tradiciones, quien [como] esclavos griegos, quien [como] siervos, quien [como] patrones, quien [como] mercaderes, y quien [como] mujeres según los casos. ${ }^{27}$

\footnotetext{
${ }^{25}$ No olvidemos, por ejemplo, los figurines diseñados por Pisanello para las cortes de Ferrara y de Mantua que inclusive lograron transformar la moda del Quattrocento en una visión casi de fábula. Pensemos también en Giulio Romano quien a partir de 1524 trabajará en la corte de los Gonzaga, no solamente como pintor sino también como organizador de estos espectáculos. Caso en el que no nos detendremos tanto, por haber sido ya ampliamente estudiado, es el de Leonardo da Vinci, activo en la corte milanesa de Ludovico el Moro, dónde, además de sus múltiples misiones como pintor, escultor, arquitecto, ingeniero militar, escritor, científico y hasta cocinero, Leonardo, al igual que muchos otros artistas contemporáneos debió trabajar también como figurinista y escenógrafo: vale decir, utilizando el término que se usaba por entonces, como apparatore. Este trabajo comprendía, entre otras cuestiones, la dirección de fiestas, el diseño de mascaradas, la creación de puestas en escena para comedias y ballets -para los cuales probablemente haya compuesto sus músicas- y la creación de autómatas, fueran éstos animales u hombres mecánicos, como el famoso león de Argentán. En relación con esta actividad leonardesca es el Códice Atlántico el que nos proporciona más datos sobre sus proyectos para las máquinas que servían para lograr la aparición de los dioses. Pensemos también en los dibujos de Luca Pacioli que pueden ser datados durante su primer período milanés, un boceto de escena humanística, donde ya se observa la impostación vitruviana, el diseño para un mecanismo de escenario giratorio que en realidad debería haber sido utilizado para una representación de Orfeo (aunque el primero se utilizó sólo en 1556 y fue introducido en el mundo del espectáculo por Baldassarre Lancia, al poner en escena los Fabi de Lotto del Mazza en el salón de los Cinquecento en Florencia). Por otra parte, nos queda el recuerdo del que fuera probablemente un embajador de Ferrara, Giacomo Trotti, quien en su Relazione nos dejó una larga descripción del modo en que Leonardo había adornado el ambiente en el cual se desarrollaron los festejos en Milán en diciembre de 1488 y enero de 1489 para las bodas del duque Gian Galeazzo Sforza con la hija del rey de Nápoles, Isabel de Aragón. Dicho espectáculo tendría tal éxito que Leonardo lo retomó con mínimas variaciones en 1518, poco antes de morir, mientras ya se encontraba en Amboise, en la corte de Francisco I.

${ }^{26}$ Angiolillo, Maria Luisa, Feste di corte e di popolo nell'Italia del primo Rinascimento. (Angiolillo, 1996, p. 66).

27 "Tucti quelli che havevano a rappresentar tucte le commoedie... vestiti tucti di vesti nove facte a posta, chi di raso, chi di zambellotto... chi di cendado, chi panni et chi subtilissime tele, habiti formati a diversi costumi, chi greci schiavi, chi servi, chi patroni, chi mercanti, et chi femine, secondo e casi." Cit. en D'Ancona, A., Op. Cit., p. 701.
} 


\section{El problema de la actuación}

Como es dable observar, todo esto nos hace comprender que, si bien en esta época, antes de la irrupción oficial de las compañías profesionales de los cómicos dell'arte -de cuya formación existe documentación fehaciente a partir de 1545-, los actores eran siempre aficionados (dilettanti), miembros de las mismas familias que ofrecían el entretenimiento ( $y$ en este sentido, es imposible olvidar el notable ejemplo de las Compagnie della Calza), a los cuales se agregaban cortesanos y pajes, ${ }^{28}$ no por esto los espectáculos podían ser considerados improvisados sino todo lo contrario. $\mathrm{Y}$, justamente, el control que sobre la totalidad de la preparación ejercía el mismo comitente nos ayuda a dimensionar mejor la importancia que tenían estos espectáculos en el ámbito de sus propios objetivos políticos.

Ahora bien, desde un punto de vista netamente "actoral" veremos que, aunque en el transcurso de estos espectáculos podía verificarse la presencia de mujeres -especialmente cantando y danzando- lo cierto es que las partes femeninas estaban destinadas, también en los espectáculos de palacio, sobre todo a los hombres. En un contexto cultural fuertemente pluricentrista, la presencia femenina en las representaciones teatrales tendría en Italia muy diversa fortuna durante los siglos XVI y XVII pues, al carecer la península de unidad política, tampoco existía una legislación homogénea al respecto y ésta podía variar enormemente de un estado al otro, y aun de una ciudad a otra. ${ }^{29}$ Con el correr del siglo y en ciertas ocasiones veremos cómo actores y músicos que bien podríamos definir como protoprofesionales se irán agregando a los elencos formados por los miembros de las familias de los comitentes. El problema más importante surgía, muchas veces, porque los nobles no se adaptaban a "actuar" junto con personas que no fuesen de su misma condición y éste es un fenómeno muy interesante porque se da fundamentalmente en las ciudades de corte y no así en el ámbito veneciano dónde, por ejemplo, la célebre Compañía de la Calza tendrá entre sus miembros a jóvenes pertenecientes al patriciado local quienes se presentarán junto con simples actores como los recordados Zuan Polo, Tagliacalze o el mismísimo Angeolo Beolco, el Ruzante quien compartía de alguna manera una doble identidad: por un lado, como dramaturgo y actor $y$, por otro, como protegido por la élite paduana representada fundamentalmente por Alvise Cornaro y algunos de los miembros más representativos de su familia. De todas formas, el ejemplo típico continúa siendo el de la ciudad de Ferrara donde, por estos años, se había logrado crear una compañía que inclusive tenía la autorización expresa del duque para actuar fuera de la ciudad. De esta manera, fue en dicha ciudad donde el teatro clásico se insertó

\footnotetext{
${ }^{28}$ Cfr. Taviani, Ferdinando, “L'ingresso della Commedia dell'Arte nella cultura del Cinquecento." En Cruciani, Fabrizio e Seragnoli, Daniele (a cura di), Il teatro... Op. Cit., p. 328.

${ }^{29}$ De todos modos, la gran oleada de "moralidad" y de disciplinamiento social se verificará especialmente como consecuencia del Concilio de Trento, abriendo paso así al "fin de la fiesta" renacentista.
} 
profundamente en la vida cultural de las clases sociales más altas, mientras éstas se servían de él como instrumento de control de los grupos subalternos.

\section{Los dueños de la palabra dramática}

Dentro de este esquema, los dramaturgos, que no son otra cosa que esos familiares constreñidos a cumplir variadísimas funciones (desde organizaciones de fiestas hasta embajadas de muy diversa índole), encuentran en la producción teatral cómica la posibilidad de poner en boca de otro una crítica mordaz al estado de cosas que debían soportar malgré soi. Me limitaré a recordar algunos ejemplos que considero particularmente válidos. En primer término, deberíamos detenernos en la Cassaria de Ludovico Ariosto, primera comedia del teatro cómico italiano, estrenada por primera vez en 1508 y revisada por su autor para los carnavales de 1529-1530, siempre en el contexto de la corte estense. En esta versión definitiva, su autor amplía el prólogo en el que plantea -a diferencia de la versión de 1508- algunas cuestiones fundamentales en torno a la posibilidad de sobrevivir en la corte, poniéndose en franco y tenso diálogo con el I Libro del Libro del Cortigiano de Baldassar Castiglione, que había sido publicado recientemente en Venecia por Aldo Manucio en 1528. Ariosto presenta dolorosamente a la belleza, a la gracia y a la juventud como una suerte de verdadera tríada, gracias a la cual los miembros de la corte, mujeres y varones, podrán permanecer en ella sin ser desechados. He aquí la larga reflexión de este Ariosto maduro vital e intelectualmente:

Esta Comedia que hoy os será recitada, si no lo sabéis, es La Cassaria, la cual otra vez, hace ya veinte años, fue vista en estos escenarios y entonces gustó mucho a todo el pueblo; ${ }^{30}$ pero no reportó un digno premio porque fue dada a inoportunos y ávidos impresores que la destruyeron e hicieron de ella lo que les vino en gana, y luego hicieron comercio de ella.

La vendieron a quien la quisiera por poco precio entre el público y los comerciantes y la trataron en un modo por el cual ya no parecía más la misma que parecía al principio.

A ella le dolió y se lamentó a su autor quien, movido a piedad por las miserias sufridas, no quiso hacerla sufrir más.

Por ello la llamó y la hizo más hermosa que nunca y la renovó tanto que quizás alguno que la había conocido antes no hubiera podido reconocerla.

Oh! Si pudiera hacer lo mismo con vosotras, mujeres!, haceros más bellas que nunca y, renovándoos a todas, volveros a la flor de vuestra edad! No lo digo a vosotras, que sois bellas y jóvenes,

\footnotetext{
${ }^{30}$ Se refiere a la primera edición (en prosa), representada en Ferrara en 1508.
} 
y no tenéis necesidad de ampliar vuestras bellezas, ni que los años vuelvan hacia atrás,

porque ahora, más que nunca, estáis en la flor de la edad;

así que sabed reconocerlos y disfrutarlos antes de que pasen.

En cambio me dirijo y hablo a aquéllas que quisieran ser aún más bellas

y no se conforman con sus bellezas:

¿qué pagarían si pudieran aumentarlas y mejorarlas?

¿Qué pagarían muchas otras que no menciono?

Las cuales, no digo que no sean bellas;

bien digo que podrían ser mucho más bellas:

y si en casa ellas tienen juicio y espejo

deberían todavía reconocer que digo la verdad,

pues existen otras infinitamente más bellas que ellas.

$Y$ poco ayudan los ungüentos y telas de Levante

que llevan consigo: porque...

si tienen la boca o la nariz más grande o más pequeña de lo necesario,

o los dientes manchados o torcidos o raros o grandes y desparejos,

o los ojos muy juntos, o las demás partes también feas,

¿qué pagarían ellas (aunque sus esfuerzos jamás podrían cambiarlas)

por transformarlas en hermosas?

Me dirijo a aquellas que solían ser tan hermosas cuando estaban en flor

sus bellos años: aquellos 16 o aquellos 20.

iOh, dulce edad, oh cruel memoria! iCómo se vuelan estos años!

De esas mujeres hablo, de las que ya han entrado en los 40, o van hacia ellos.

¡Oh nuestra lábil vida! iOh! iCómo vemos precipitarse la belleza y la gracia

sin poder encontrar el modo de recuperarlas [pues] ni empolvándose ni maquillándose

se podrá lograr que esos años regresen: ni haciendo tratamientos que estiren la piel

o mejoren los órganos se podrá hacer algún día que se escondan las malditas arrugas

que cubren el rostro y el pecho y aún más otras partes que no se muestran.

Pero para no tocarlas siempre, para no estar continuamente encima de estas mujeres

(aunque se dejen tocar y permitan que se les esté encima, por lo que no se molestan, tal es su naturaleza tan dulce y agradable), quiero decir aún dos palabras a los jóvenes,

sobre todo a los de las Cortes, que tienen siempre el deseo de ser jóvenes y galantes

al igual que las mujeres. Y tienen razón, pues bien saben que en la Corte, sin belleza y sin gracia no se adquieren ni favores ni riqueza. ${ }^{31}$

Otros, por otras vías quisieran ser bellos: no voy a buscar los motivos por los cuales lo desean, pero es más tolerable este deseo entre los jóvenes que entre los viejos

y sin embargo, algunos viejos buscan el modo de ser bellos y prolijos, y cuando

sus cuerpos se debilitan (y se vuelven decrépitos hacia el final de sus vidas),

tanto más fresco, ardiente, libidinoso y arrogante se convierte su ánimo.

Repiten los mismos discursos, los mismos pensamientos, los mismos deseos

\footnotetext{
${ }^{31}$ Recordemos aquí que el libro de Baldassar Castiglione (1478 - 1529) El Cortesano había sido publicado por primera vez en Venecia en la primavera de 1528 por Aldo y Andrea Manuncio y pocos meses más tarde en Florencia por los herederos de otro gran editor de esos días: Filippo di Giunta. La necesidad de establecer las características, valores y límites del perfecto cortesano será una tópica omnipresente entre estos autores que, en las cortes, cumplen una doble función, a saber: como miembros de la misma y como sus propios narradores. Además, no olvidemos que luego de una dedicatoria general hecha por Castiglione al embajador portugués don Miguel de Silva, obispo de Viseo, el primer libro en que se divide El Cortesano es dedicado por su autor (a partir de la edición de Aldo Manucio de 1528) a Messer Alfonso Ariosto (14751525), pariente de Ludovico, íntimo amigo de Castiglione y modelo, para él, del perfecto cortesano.
} 
y las mismas ansias de cuando eran jóvenes: así hablan de amor, así se pavonean de realizar grandes hazañas, así se perfuman como nunca antes y se muestran vestidos con adornos superfluos y con encajes y, para esconder su edad, se quitan los pelos blancos del rostro y de la cabeza; algunos se los tiñen: hay quien lo hace de negro y quien de rubio pero al cabo de dos o tres días vuelven a verse blancos. Otros esconden su calvicie bajo un sombrerito, otros con peluquines postizos tratan de mostrarse jóvenes; otros se hacen afeitar dos veces por día: pero de poco sirve que nieguen la propia edad cuando el rostro los delata, mostrando la cantidad de años, a través de las arrugas que circundan los ojos, o de los ojos enrojecidos y vidriosos, o de los dientes que se caen o que ya les faltan en gran número, y que quizás faltarían en su totalidad si no los ataran y con mucho trabajo los mantuvieran por la fuerza en la boca. ${ }^{32}$

¿Qué pagarían éstos si alguien les hiciera lo mismo que este Autor ha hecho con su Comedia! ¡Cualquier tesoro, cualquier premio les parecería una pobre recompensa!

Pero si el Autor de esta Comedia pudiera brindar tal servicio a las mujeres y a los hombres, el cual ya les he dicho ha hecho con su Obra (la cual ha renovado por completo, haciéndola más bella), sin otra paga u otro premio lo haría a vosotras, señoras, pues desea daros el mismo placer que desea para él mismo.

Pero muchas cosas que son fáciles para uno resultan difíciles para otro.

Así, si por su propia decisión le fuera posible hacer a los hombres y a las mujeres más hermosos y más jóvenes, como a sus propios relatos, ya se hubiera convertido en un joven tan bello y galante, capaz de gustar a los demás tanto como él desea que os guste su Cassaria.

Mas si esto no puede hacerlo por él mismo, creed que no lo puede hacer siquiera por Vosotros: si pudiera, os digo de parte suya que lo haría con placer.

Otro caso interesante y si se quiere opuesto al que hemos citado supra es el de Angelo Beolco, el Ruzante (Padua, 1502?-1542), dramaturgo fuertemente provocador y prácticamente olvidado hasta la segunda mitad del siglo XIX. Éste, contrariando el triunfo de la tesis lingüística de Pietro Bembo (quien, en sus Prosas de la lengua vulgar, publicadas en Venecia por Aldo Manuzio en 1525, había afirmado que el volgare debía seguir los ejemplos de Petrarca, en poesía y Boccaccio, en la prosa), escribe la mayor parte de su obra en el complejo dialecto de su propia tierra, el pavan, y pone en escena, prácticamente por primera vez en la historia del teatro italiano moderno al campesino iletrado y rústico, obligado por circunstancias ajenas a su propia voluntad a peregrinar hacia la ciudad que lo burla y lo rechaza. Naturalmente, también aquí, el discurso dramático tendrá como receptores tanto a los señores como a los grupos subordinados. En estos posibles contextos, casi todas las obras de Ruzante nos hacen pensar -de una manera u otra- en las

\footnotetext{
${ }^{32}$ Esta tópica de la edad se encuentra en muchos escritos de Ariosto y de modo especial en sus Sátiras (1517 - 1525), donde el poeta desea mostrarnos cómo ciertas acciones hechas por un viejo pueden caer en el ridículo. En este sentido, vide Satira V. A Messer Annibale Malegucio $(1519$, ca.). Además, es interesante recordar que en la primera edición de la comedia, escrita en prosa en 1508, Ariosto no se detiene en este tópico, mientras sí lo hace en la versión definitiva, que se publica varios años después de la aparición del Elogio de la locura de Erasmo de Rotterdam (1511). En él, el gran humanista hace decir a la Locura que "mucho más gracioso todavía es ver a ciertas ancianas que apenas pueden con el peso de sus años y semejan cadáveres, que se diría han vuelto del infierno [...] maquillan exageradamente su cara, no se apartan nunca del espejo, depilan el monte de Venus, hacen ostentación de sus pechos lacios y ajados, con voz trémula e insinuante tratan de hacer revivir una pasión que se extingue, beben, bailan entre las jovencitas, y hasta escriben pequeñas cartas de amor." Vide Erasmo de Rotterdam, Elogio de la locura. Madrid, Alianza, 1995, p. 70. Queda sin embargo claro que Ariosto, como familiar en la corte estense de Ferrara no podía utilizar el mismo tono que usa el autor del Elogio... De los mismos años, podemos recordar un óleo atribuido a Quentin Metsys (1465 - 1530) (pariente de Cristoforo da Messibugo, organizador de los banquetes de la corte de la familia Este), "Vieja grotesca", perteneciente a la Galería Nacional de Londres.
} 
tensiones existentes entre espectáculo, teatro y comitencia. Sin embargo, centraremos nuestra atención en dos de ellas que, equivocadamente, la crítica ha considerado durante largo tiempo como una mal llamada "producción menor": nos referimos a sus dos Oraciones -la primera dirigida al cardenal Marco Cornaro y la segunda a su hermano menor, el cardenal Francesco Cornaro. Dichas obras forman parte de su producción escénica y pueden ser estudiadas como verdaderos prólogos teatrales, si bien es cierto que también pueden ser analizadas dentro del contexto de los modelos tradicionales de la oratoria del siglo XVI -frente a la que seguramente Beolco no podía en ningún caso permanecer insensible, dada su pertenencia -si bien como prematrimonial- a una familia íntimamente ligada al ateneo paduano.

1. La Primera Oración, compuesta como hemos dicho en homenaje al cardenal Marco Cornaro, data, casi sin ninguna duda, del $1521^{33}$ y en ella son rápidamente identificables ciertos topoi que acompañarán al comediógrafo durante toda su carrera. Así encontraremos su polémica con los literatos asociados al mundo urbano y a la tradición bembesca que, en la famosa cuestión de la lengua -centralísimo debate de la élite intelectual italiana de la primera mitad del siglo XVI- apoyaba el uso del volgare florentino (que Ruzante, irónicamente llamará moscheto ${ }^{34}$ ):

"...No he querido venir a haceros este discurso a Padua [...] porque esos malditos charlatanes y cagones literatos lo hubieran tomado a mal. [...] Ni debéis hacer caso que hayamos querido mandar a un sacerdote o a uno de esos tales de los cinturones color azafrán ${ }^{35}$, que hablan según la gramática o en lenguaje florentino, de esos, sabéis, que se llaman doctores. [... $]^{\prime \prime 36}$

A lo que agregará la principalísima cuestión del "derecho natural" de los campesinos de hablar en su propia lengua y de defender su lugar de nacimiento

“...Nosotros tenemos placer de tener nuestro natural derecho en pie por la naturaleza mientras estemos vivos, moviendo la lengua a nuestro modo y no a la florentina. $Y$, tanto por decir de mí, yo no cambiaría mi lengua [paduana] por doscientas florentinas, ni aceptaría haber nacido en Egipto de Bethelem, donde nació el Señor Jesús Dios, por no haber nacido en el Paduano."37

Ahora bien, esta exaltación por la propia tierra, acompañada por una exhaustiva enumeración de todas las "buenas cosas" que pueden ser encontradas en el territorio paduano (frutos, árboles, animales y

\footnotetext{
${ }^{33}$ Salvo la explicación dada por el diarista Sanudo que habla de ella ya en 1520.

${ }^{34}$ Pensemos que Beolco escribirá una de las obras de su madurez, La moscheta, haciendo referencia a este modo de hablar delicado y elegante. Según Ludovico Zorzi esta obra es, justamente, la obra maestra del teatro ruzantiano. De ella no se ha encontrado --al menos hasta ahora- el manuscrito original, por lo que nos es incierta la fecha en que fue escrita. La primera edición fue editada póstuma, en Venecia en 1551 por el tipógrafo Stephano de Alessi.

${ }^{35}$ Los doctos y los personajes de alto rango solían usar entonces cinturones dorados o de color amarillo azafrán. Cfr. Zorzi, Ludovico, en Ruzante, Prima Oratione al Reverendissimo Cardinal Cornaro Vecchio. Op. Cit., p. 1555.

${ }^{36}$ Ibídem, p. 1184.

${ }^{37}$ Ibídem, p. 1184.
} 
mujeres, -comparadas éstas últimas, como siempre, con las naturales bellezas del propio universo campesino-) dejan entrever, por un lado, la idea del contraste existente entre la ciudad y la campaña cuestión centralísima en la dialéctica social del siglo XVI- y, por otra parte, nos acerca el concepto de que las bondades de esa vida no eran tales. Pienso que esta suerte de "dualidad discursiva" encuentra sus raíces más profundas en la misma dualidad cultural de Beolco quien, ligado como estaba a la élite representada en su caso por el círculo de Alvise Cornaro, se "enmascara" en su personaje de Ruzante para mostrar el conocimiento que tenía del mundo campesino, gracias a sus contactos directos con los habitantes del hinterland paduano. $\mathrm{Y}$ si es difícil pensar que sus escritos hayan escondido el único objetivo de hacer presente una fuerte crítica social que pudiera golpear las conciencias de aquellos a quienes iban dirigidos, al menos es evidente que aparece en su obra una serie de "situaciones de hecho" que, a distancia de casi cinco siglos, agilizan la "lectura" que podemos hacernos de ese cosmos. Así, por ejemplo, el pedido que Ruzante hace -usando sugestivamente la primera persona del plural- al cardenal Cornaro de que implante nuevos estatutos y leyes, nos muestra que ni siquiera todas las bellezas de la tierra paduana sirven para mitigar las miserias a las que debe hacer frente el campesino cada día de su vida: la obligación de tener que cumplir con ciertos preceptos religiosos que regulaban no sólo su conciencia individual sino también su trabajo y su tiempo de ocio:

"Queremos que nos hagáis ciertas leyes y estatutos nuevos, que son muy justos y necesarios, os lo aseguro.

La primera ley es que cada cazador o pajareador, que va por su placer y no por ganar cazando [...], pueda ir el domingo sin escuchar la misa, y que eso no sea pecado, pues, como sabéis, a esa hora es lo bello del placer, por más razones; y quien pierde esa hora no la recupera.

Ruzante plantea aquí un problema -el de la libertad de la caza y de la pesca- que era muy discutida por entonces, tanto que, en 1525, los campesinos del Sud-Tirol y del Trentino se habrían rebelado por este motivo y finalmente habrían conseguido ciertos derechos en este sentido. El teatro lleva a escena las inquietudes cotidianas y le da voz a los oprimidos...

La segunda es que ningún campesino sea obligado a ayunar pues, como Vos sabéis, el fatigarse hace digerir las piedras; y cuando se ha digerido, a quien no come se le pierde el corazón y se corre el riesgo de morir y de escupir el pulmón, por la saliva que te viene a la boca. Luego vas a la cama, no puedes dormir y, si tienes mujer, para sacarte el hambre y hacerte venir el sueño, haces eso que no harías, porque dormirías. Y si no tienes mujer, es raro que al día siguiente no tengas una; y por no estar ocioso, se hace peor, como vos sabéis, ¿entendéis? ${ }^{38}$

\footnotetext{
${ }^{38}$ En relación con el tema de "lo bajo" en la literatura del Renacimiento, ver Bajtin, Mijail. (1987). La cultura popular en la Edad Media y en el Renacimiento. El contexto de François Rabelais. Madrid: Alianza Estudio. En realidad, no es éste el único momento en que Beolco hace este tipo
} 
La tercera ley es que en la época de la cosecha no sea pecado trabajar [el día de] la fiesta, porque de un momento a otro puede venir una ráfaga de tormenta y arruinarnos del todo. Luego maldecimos como perros; ¿̇y quién no maldeciría, decidme, por vuestra fe? Es necesario entonces que vayamos a robar, si queremos vivir, y de este modo cometemos doble pecado y no tenemos la culpa. $Y$ sin embargo es así.

La cuarta es que se pueda comer por la mañana antes de la misa, para poder estar luego con el corazón [en el] Señor Jesús Dios. [...] Y si habremos comido, tendremos el corazón allí [en el] Señor Jesús Dios y no en casa [en el] pan.

La quinta es que no sea pecado de gula comer cuando place, aun si no se tiene hambre; porque los médicos dicen que aquello que gusta hace bien, haciendo bien [da] salud, estando sanos se vive mucho, viviendo mucho se viene viejo, viniendo viejo se hace el bien, y haciendo el bien se va al Paraíso. [...]

La sexta ley es que hagáis que cada sacerdote pueda tener mujer, o que sean castrados, porque es una maldición la fragilidad de la carne [...] y si bien son sacerdotes, ellos son hombres como [lo] somos nosotros, y algunos aun más machos; y al no tener mujeres, tienen tanta calentura que cuando se encuentran [por] primera vez con una de nuestras mujeres, de hecho la embarazan, y nosotros pobrecitos, mantenemos a sus hijitos, lo que no es justo. Si ellos son castrados, nosotros no tendremos esta preocupación sobre nuestras espaldas, y si tienen mujer, no estarán más tan rabiosos y siempre así calientes, porque ellas los tendrán ordeñados; y si también embarazan a nuestras mujeres, nosotros embarazaremos a las de ellos, y si mantenemos a sus pequeños, también ellos mantendrán a los nuestros, y así estaremos iguales.

La séptima ley es que hay una gran maldición de enemistad y de maldad entre nosotros campesinos de las villas y los ciudadanos de Padua, que nos comen el corazón y todo el día por esto nos preocupamos. [...] Ellos nos dicen a nosotros campesinos, villanos, culebras, ranas; y nosotros les decimos a ellos cagones, perros, usureros, chupasangres de los pobrecitos. Quisiéramos, pues, (ya que, como ya he dicho, estamos nosotros en la parte de abajo) que acomodaseis estas diferencias, y hagáis que fuésemos una misma cosa. Queremos por eso que Vos nos hagáis esta ley, que cada villano pueda tomar cuatro mujeres, y que cada villana pueda tomar cuatro maridos; porque cuando esos cagones de Padua vean esto [...] todos, para poder tener cuatro mujeres, se harán villanos [...]. Y todas las ciudadanas (pues a ellas les agrada), para poder tener cuatro hombres se harán villanas, y nosotros sacaremos provecho. $Y$ de este modo seremos todos una misma cosa, y no habrá más envidia y enemistad, porque haremos todos una única parentela. $Y$ todas las mujeres irán grávidas, $y$ se cumplirá la ley del Señor Jesús Dios que dice: "Creced y multiplicaos." [...] Se verán sólo cielo y mujeres encintas y niños y muchachos. No [...] se cometerá ese pecado (que no debería ser pecado) de ir a las mujeres ajenas, porque todos tendrán que hacer en la propia casa.." ${ }^{39}$

de apreciaciones "escatológicas" en sus escritos. Así por ejemplo, podríamos citar el Dialogo facetissimo, en el cual Menego, refiriéndose a la carestía y al hambre dice que "si una vez comido, se tapara el agujero de abajo, la comida no podría salir y las tripas quedarían llenas, y así no vendría tanta hambre." Ruzante, Teatro. Op. Cit., p. 692. Por otra parte, hemos encontrado en su obra referencias explícitas a la práctica del bestialismo -aparentemente común en este mundo rural. (Cfr. Anconitana. Actos II y IV). Lo que nos resulta realmente sugestivo es el modo en que Ruzante formula esta pregunta al cardenal Cornaro en modo ciertamente cómplice y francamente intimista. También es interesante observar una evolución en el lenguaje de nuestro autor. Así, Beolco pasa de referirse "implícitamente" en su Primera Oración de 1520 a ciertas prácticas debidas al "hambre y al ocio" del hombre que está solo, a decir explícitamente en su Anconitana de 1529-30 o 1534, obra ésta de su madurez, de qué modo andaba con las bestias para divertirse. Teniendo en cuenta las fechas en que fueron escritas estas obras, nos preguntamos si este cambio de impostación lingüística pudo deberse al agravamiento de la polémica entre clasicistas y anticlasicistas -grupo éste último en el inscribimos a nuestro autor. El hecho de que Beolco hubiera elegido explicitar ciertas cuestiones a partir de fines de la década del '20 podría responder a este planteo.

${ }^{39}$ Ruzante, Prima Oratione...Op. Cit., pp. 1199-1203. 
Como se puede observar, los ejemplos reportados arriba nos muestran claramente cómo en la cosmovisión del campesino -representado aquí por Beolco-Ruzante-se hace siempre presente el temor al hambre y a las posibles consecuencias que el engaño ejercido por los habitantes de la ciudad podrían tener sobre su vapuleada persona. Pero será justamente este último motivo el que refuerza la necesidad de pasar de meros "objetos" a verdaderos "sujetos" de su propia historia, en la que la creación de una suerte de gran "parentesco universal" los verá, finalmente, protagonistas de la Historia con " $\mathrm{h}$ " mayúscula.

\section{La Segunda Oración dedicada al Ilustrísimo Señor Francisco Cornaro Cardenal fue escrita} por Beolco en ocasión del acceso de aquél al cardenalato, el 20 de diciembre de 1527 (aunque su nominación se hizo pública sólo en febrero del año siguiente). Al igual que la Primera Oración, aquélla también fue recitada por primera vez en la villa asolana del Barco. Sin embargo, como veremos inmediatamente, el tono utilizado por Beolco en esta segunda oportunidad se nos revela mucho más serio y oscuro. Ludovico Zorzi explica esta diferencia a partir de las disímiles personalidades de ambos hermanos aunque, según él, además, "en la divergencia entre las dos personalidades de Marco y de Francisco Cornaro se puede recoger un reflejo de la profunda transformación de la sociedad véneta ( $y$ en general italiana) en un período relativamente breve. La crisis renacentista [...] culmina [...] hacia finales del tercer decenio [del siglo XVI]: las guerras, la Reforma, la ruptura del equilibrio económico son las causas más evidentes. Tampoco el movimiento regresivo de la sociedad italiana está separado, al principio, de un vago sentimiento de agitación y de perturbación espiritual." ${ }^{40}$ Además, los ocho años que habían transcurrido desde la Primera Oración mostraban de qué manera las condiciones de vida habían empeorado sensiblemente. Así es posible comprender mejor este tono más melancólico pero a la vez más histórico de ciertos pasajes de esta

\section{Segunda Oración:}

"Vos sois de una raza [...] similar a la del pater familias [...] que va quitando las espinas, las zarzas y las hierbas que dan mal olor; ${ }^{41} \mathrm{y}$ ahora hay muchas en la Cristianidad, y tantas, comenzando por ese fastidioso alemán Martinello dal Liutolo (la cursiva es nuestra) ${ }^{42}$. Pero [...] espero que si él suena su laud $^{43}$, vos lo haréis bailar otro sonido, a él y a todos aquellos que le van detrás, aún de este país;

\footnotetext{
${ }^{40}$ Zorzi, Ludovico. En: Ruzante, Teatro. Op. Cit., p. 1568.

${ }^{41}$ Esta imagen nos hace presentes dos parábolas evangélicas que evidentemente Beolco utiliza aquí para continuar el tono laudatorio utilizado en relación con el cardenal Cornaro. Me refiero a la parábola del padre de familia y los obreros de la vid (Mateo, XX 1-16) y a la del sembrador (Mateo, XIII, 24-30).

42 Juego de palabras que hace Ruzante para nombrar a Martín Lutero. Por otra parte, recordemos también que el martinello es el instrumento usado para tensar las cuerdas del laúd. Por entonces era común entre las clases populares confundir los nombres que podían resultar complicados. En relación con Lutero, se solía jugar también con la idea de Lutero y de luto (del latín, lutum o sea barro), para resolver "de forma humanista la cuestión de la condena del movimiento luterano, sin entrar en discusiones teológicas." Para una explicación más exhaustiva de este último topos, ver Prosperi, Adriano, "L'eresia in città e a corte". En AA.VV., La corte di Ferrara e il suo mecenatismo, 1441-1598. (Prosperi, 1990, pp. 267-281)

${ }^{43}$ Aquí se presenta la idea del engaño, de la seducción que, según Beolco ejercía Lutero sobre las almas de los simples, a través de la ejecución de la música. Cfr. esta idea en Da Ponte - Mozart, Las Bodas de Fígaro, cuando, en el primer acto, Fígaro, para contestar el engaño del Conde de Almaviva canta la celebérrima: "si quiere cantar, señor condesito, la guitarrita os tocaré."
} 
pero hay tantos que no se quieren confesar más, que no hacen más vísperas, que non van jamás a la Iglesia y no miran jamás a otras figuras si no son aquéllas que se encuentran en las cartas." ${ }^{44}$

Ésta y otras cuestiones son, para Ruzante y para los demás hombres por los que decide elevar su voz, motivo de profunda tristeza:

"También por esto creo que el Señor Jesús Dios ha mandado tantas tribulaciones y tantas adversidades sobre la tierra; este mundo se ha trasformado ahora en un país donde puede decirse: "bienaventurados los muertos, que han muerto en la paz del Señor", porque ahora no se escucha hablar [más] que de guerra, de ruinas, de muerte, y desde la época de las fugas hacia aquí, estamos reducidos peor que nunca. [...]. Todos han perdido el canto." 45

Como no podía ser de otra manera, el topos del hambre se hace aquí nuevamente presente, y su presencia no querida modifica implacablemente el universo campesino, limitándolo aún más:

"En conclusión, este mundo se ha transformado en una tierra inculta. Mirad si veis aún a un enamorado. Os sé decir que el hambre les ha echado el amor del culo. Nadie osa enamorarse más, para no asumir gastos en casa; y esos sollozos y esos suspiros que se solían confundir con [el] amor, ahora [se confunden] con el hambre." ${ }^{46}$

Ruzante muestra entonces al cardenal Cornaro cómo las antiguas seguridades del mundo han cesado y nuevamente podemos observar aquí cómo las esperanzas de una vida mejor, presentes en la Primera Oración, han desaparecido:

"Todas las buenas costumbres se han perdido, y, cuando alguien muere, ahora, [i]mira si se mojan muchos pañuelos para irle detrás llorando[i]." ${ }^{\prime 7}$

Pero claro, no debemos olvidar que estamos analizando una oración laudatoria, y, como tal, la gravedad de la situación descripta por Beolco podrá ser transformada justamente a partir del futuro accionar del cardenal, ensalzado aquí como nuevo paladín de la Iglesia Católica. Al igual que en la Primera Oración, Ruzante sugiere a Cornaro una serie de medidas "cuando será Papa" que contribuirán seguramente a mejorar no sólo este caótico estado de cosas sino a olvidar el terror que la presencia de los soldados alemanes causaba entre el campesinado:

\footnotetext{
${ }^{44}$ Ruzante, Seconda Oratione, all' Illustrissimo Signor Francesco Cornaro Cardinale. Op. Cit., p. 1211. Recordemos aquí que los juegos de cartas tenían por esos años un gran éxito a partir de la difusión que les dieron los lansquenetes alemanes de Carlos V. Beolco se refiere además a la abolición que hizo Lutero del culto de los santos, representados iconográfica y escultóricamente a través de las imágenes.

45 Ibidem, p. 1211.

${ }^{46}$ Ibidem, pp. 1211-1213.

${ }^{47}$ Ibidem, p. 1213.
} 
"Un día seréis Vos el que deberá acomodar este mundo, y queriéndolo acomodar, es necesario que quitéis [del medio] a todos aquellos que lo arruinan. $Y$ de todas las naciones del universo, no hay ninguna peor, ni que arruine más, [que la] de estos ultramontanos alemanes lanza-cannelle (sic). ${ }^{48} \mathrm{Y}$ porque cuando [el] Señor Jesús Dios hizo el mundo, hizo una buena empalizada entre ellos y nosotros, y un enrejado y un buen cercado alto ${ }^{49}$, con la intención de que se quedaran de su lado y no pudieran venir a fastidiarnos, este mundo habría quedado en orden y ellos no hubiesen sabido jamás encontrar la ruta para pasar de nuestro lado, si no hubiera llegado el perdón de Roma, por el que los hemos dejado venir de uno a uno, de tres en tres, de diez en diez. [...] Por esto quisiera, Monseñor, que [les] quitáramos estos senderos. [...] Quisiera que cuando estéis en Roma, para que ellos no vengan más con la excusa del perdón, [les] mandéis el perdón desde Roma, del otro lado de las montañas. [...] Y cuando tuvieran el perdón de aquel lado [...] el paso se cerraría, ellos mismos olvidarían el camino para venir y nosotros estaríamos seguros." ${ }^{50}$

Ruzante, en otro intento de velar por la estabilidad, retoma en esta Segunda Oración la idea de formar un único parentesco tal como lo hemos visto en la Primera Oración:

"Quisiera, por tanto, que hagáis que haya sólo una ley única y fuerte, que no se pudiera deshacer, y [que la hicierais] tan grande que todos la pudieran ver y conocer, y todos se gobernaran según aquélla." ${ }^{51}$

Sin embargo, Beolco agrega aquí un elemento verdaderamente novedoso, al pedir ser convocado junto a sus pares para contribuir a la creación de dichas leyes, pues así se evitará que el villano pueda ser engañado como siempre lo había sido hasta entonces:

"y si aún no se pudiese hacer con una sola y hubiese necesidad de más (porque el mundo es grande), quisiera que las rehicierais y [que] llamarais también a nosotros de las villas, para que no seamos engañados. Nosotros no tenemos una ley de nuestra parte, ni que hable por nosotros, ni [nadie entre nosotros] la ha hecho. [...] Si también nos llamáis a nosotros, haremos también nosotros las nuestras; y si hiciereis una sola, nos gobernaremos todos según aquélla, porque sé que la haréis derecha, justa e igual." ${ }^{52}$

Dos últimos topoi, el del hambre y el de la usura-, aparecen en el texto antes de que el Ruzante-actor decida mostrar a su homenajeado sus dotes histriónicas interpretando la canción que cierra el texto. Ambos temas se asocian fuertemente con la posibilidad de contar o no con un elemento material indefinido, la roba ${ }^{53}$, el que, de alguna manera, parecería definirse verdadero eje de la vida de los hombres y que

\footnotetext{
${ }^{48}$ El horror que habían creado estos soldados alemanes, especialmente luego del saqueo de Roma, en mayo de 1527, se hace aquí nuevamente presente. Recordemos que los lansquenetes habían aparecido por primera vez en Italia justamente en 1509, como mercenarios del ejército de Maximiliano de Austria, empeñado en el asedio de Padua.

${ }^{49}$ Se refiere a la cadena alpina.

${ }^{50}$ Ruzante, Seconda Oratione... Op. Cit., p. 1215.

${ }^{51}$ Ibidem, p. 1217.

52 Ibidem, p. 1216.

${ }^{53} \mathrm{Cfr}$. la escena III del Parlamento..., donde Ruzante hace mención al temor que tiene Gnua de no tener roba.
} 
representa cualquier cosa tangible, incluida la posesión de una mujer:

"Dice [el] Señor Jesús Dios a nuestro padre Adán y también a todos nosotros que les hemos venido detrás: 'tú te ganarás el pan con el sudor de tu frente.' Pero me parece que ahora sea de otro modo, que nosotros que sudamos, no lo tenemos jamás y [que] los otros que no sudan, lo comen. [...] Y es necesario, si queremos vivir, que lo tomemos siempre con usura. ${ }^{54} \mathrm{Y}$ pues el dar con usura es un gran pecado, se encuentran pocos que lo den, y aquellos pocos, por un tan grande pecado, quieren tener una gran ganancia. [...] Por eso quisiera, por el bien de cada uno, que quien tuviese, pudiera dar con usura por un precio honesto, y no a más valor; y que el dar con usura no fuera pecado, sino mérito, para ayudar a los pobrecitos [...] porque sabéis que el hambre hace cometer las peores cosas. [...] ¿Qué sería necesario hacer? Os lo diré. Quiero que hagáis que los judíos puedan convertirse en cristianos sin dejar sus cosas (roba), porque todos [se convertirían] si no fuese por no perder sus cosas $(\text { roba })^{55}$; y las cosas (roba), creo que lo sabéis, es la primera sangre y el primer elemento natural." ${ }^{56}$

\section{Conclusiones}

Como se desprende del análisis que hemos intentado realizar en estas páginas, hemos visto cómo la comedia prevaleció sobre la tragedia o sobre otros géneros dramáticos -como la fábula pastoral que será característica de los años inmediatamente posteriores al período por nosotros estudiado. Y es aquí donde entra en escena la figura del dramaturgo quien, por medio de sus escritos establece diversas relaciones, ora complacientes, ora enjuiciadoras frente al poder político del que no puede apartarse por ser justamente la corte o el gobierno republicano su principal comitente. En el ámbito témporo-espacial que hemos analizado, las dos figuras más relevantes fueron, sin duda, las de Ludovico Ariosto y la de Angelo Beolco. El primero, poeta-cortesano, cuya producción escénica fue valorada por la crítica a lo largo de casi cinco siglos de manera muy dispar, continúa siendo considerado como el fundador de la comedia regular italiana, señala una primera ruptura con la tradición humanista que pretendía tan sólo vulgarizar -vale decir traducir al vulgar italiano- las comedias latinas de Plauto y Terencio. Ariosto, al servicio de la familia Estense, sin embargo, debió mantenerse casi siempre dentro de los límites impuestos por su condición de familiar de los señores de Ferrara y es por eso que su crítica a ciertos aspectos de la sociedad de su tiempo puede

\footnotetext{
${ }^{54}$ El tema de la legitimidad de la usura (con un interés equitativo) era un motivo fuertemente debatido en la edad de la Reforma. Por lo que respecta a Ruzante y su vinculación con la usura como administrador de Alvise Cornaro, recuérdense los famosos dichos de su amigo Sperone Speroni degli Alvarotti (Padua, 1500-1588), quien en su Diálogo de la Usura, ésta, personificada como una diosa, se dirige a Ruzante diciéndole descarnadamente

"Pobre mi Ruzante, ¿'es este el lecho en el cual duermes, en lo de un par tuyo, que en gentileza de hacer comedias rusticanas eres sin par en Italia? ¿Ésta tu capa, que llevas encima como una manta durante la noche, o no es acaso la misma que llevas sobre ti cada día, en verano y en invierno, en Padua? ¿Quién te descalza en la noche? ¿Quién enciende el fuego en tu habitación? ¿Quién saca agua? ¿Qué bebes? ¿Qué comes? ¡Pobre de ti! O sea imezquino, infeliz! Tú haces comedias de amores y de bodas campesinas con las que ríen los grandes señores y no te preocupas por la tragedia que hace de ti tu pobreza llena de horror y compasión."

${ }^{55}$ En el momento de convertirse a la fe cristiana, era obligatorio para los hebreos que cedieran una gruesa parte de su patrimonio a alguna congregación religiosa o a otra obra pía, como mecanismo para expiar las pluriseculares culpas de las que era acusado el pueblo hebreo por la Iglesia católica. Es por esto que Ruzante considera que habría más conversiones si no se les obligara a abandonar su patrimonio.

${ }^{56}$ Ibidem, pp. 1217-1219.
} 
encontrarse en escritos que podríamos definir como autobiográficos -sus Sátiras, por ejemplo- pero mucho más tangencialmente en sus obras destinadas a la representación escénica, a la que asistían sus mismos comitentes. Sólo una vez asentado en el seno de la corte, el poeta pudo permitirse ciertas digresiones en torno de la sociedad de la que él mismo formaba parte: sin duda, la recreación casi total del prólogo de $L a$ Cassaria (versión de 1530) puede corroborar, como hemos visto esta hipótesis. Angelo Beolco, el Ruzante (dramaturgo), en cambio, hará subir a escena a su Ruzante (personaje), frente a los invitados de su protector y comitente, Alvise Cornaro, quienes tendrán así, a partir de estos textos teatrales una visión de esos campesinos del hinterland paduano que, en la primera mitad del siglo XVI, parecían haber perdido completamente las esperanzas de mejorar sus ya paupérrimas y desgraciadas condiciones de vida.

\section{Referencias Bibliográficas:}

\section{Primarias}

ARIOSTO, Ludovico. (1962). Commedie. (Volumen I). Milán: Bur.

---. (1997). Commedie. La Cassaria - I Suppositi. (En prosa). Edición de Luigina Stefani. Milán: Mursia.

---. (s/f). Commedie e Satire. (Con un prefacio de Massimo Bontempelli). Milán: Istituto Editoriale Italiano.

---. (1997). La Cassaria. (Traducción integral, introducción y notas de Nora Hebe Sforza). Colección de Libros raros, olvidados y curiosos. Buenos Aires: Facultad de Filosofía y Letras de la Universidad de Buenos Aires.

---. (1930). Le Satire e scelta delle Commedie. (Con introducción, comentarios y notas de Antonio del Piero). Milán: Carlo Signorelli Editore.

---. (1936). Opere minori. Florencia: Adriano Salani Editore.

---. (1963). Opere minori. En la colección: La letteratura italiana. Storia e testi. (Compilada por Cesare Segre). Milán: Riccardo Ricciardi Editore.

BEOLCO, Angelo (llamado el Ruzante). (1967). Teatro. Primera edición bilingüe (paduano - italiana) completa. Texto, traducción y notas de Ludovico Zorzi. Turín: Einaudi editore.

---. (1967). Reduce, Bilora, Menego, Moschetta, Fiorina, Anconitana, Prima Orazione. Edición compilada por Gian Antonio Cibotto. Incluye la versión teatral de II Reduce, ovvero Parlamento de Ruzante che jera vegnu da campo de Cesco Baseggio (1967). Milán: Longanesi \& Co.

CASTIGLIONE, Baldesar. (1990). // Cortigiano (1528). Milán: Garzanti. 
MESSISBUGO, Cristoforo da. (1960). Banchetti composizioni di vivande e apparecchio generale (1549). (Edición de Ferdinando Bandini). Venecia: Neri-Pozza.

\section{De Consulta}

ALTIERI BIAGI, Maria Luisa. (1980). La lingua in scena. Boloña: Zanichelli.

AMBROSINI, Federica. (1996). "Cerimonie, feste, lusso." En: AA.VV., Storia di Venezia. Dalle origini alla caduta della Serenissima. Vol. V: Il Rinascimento. Società ed economia. (Volumen compilado por Alberto Tenenti y Ugo Tucci). Roma: Treccani.

ANGIOLILLO, Maria Luisa. (1996). Feste di corte e di popolo nell'Italia del primo Rinascimento. Roma: Edizioni SEAM.

ATTOLINI, Giovanni. (1997). Teatro e spettacolo nel Rinascimento (1988). Bari: Laterza.

BAJTIN, Mijail. (1994). La cultura popular en la Edad Media y el Renacimiento. El contexto de François Rabelais. Buenos Aires: Alianza Estudio.

BARATTO, Mario. (1985). “L'avventura teatrale di Ruzante.” En: Garbero Zorzi, Elvira; Romagnoli, Sergio (comps.), Scene e figure del teatro italiano. Imola: Società Editrice II Mulino.

BATTISTI, Eugenio. (1962). L’Antirinascimento. Milán: Feltrinelli.

BONORA, Ettore. (1966). “La commedia italiana.” En: Cecchi, Emilio y Sapegno, Natalino, Storia della letteratura italiana. Volume IV: II Cinquecento. Milán: Garzanti.

BORSELLINO, Nino; MERCURI, Roberto. (1972). Il teatro del Cinquecento. Bari: Laterza.

BULLEGAS, Sergio. (1993). Angelo Beolco. Alessandria: Edizioni dell’Orso.

BURKE, Peter. (1995). El Renacimiento italiano. Cultura y sociedad en Italia (1986). Madrid: Alianza Forma. 
---. (1995). “Il Cortigiano” (1988). En: Garin, Eugenio (compilador). L'uomo del Rinascimento. Bari: Economica Laterza.

---. (1996). La cultura popular en la Europa moderna (1978). Madrid: Alianza Universidad.

COZZI, Gaetano; KNAPTON, Michael. (1986). "La Repubblica di Venezia nell'età moderna. Dalla guerra di Chioggia al 1517." En: Galasso, Giuseppe, Storia d'Italia. Vol. XII - Tomo I. Turín: UTET.

CRUCIANI, Fabrizio. (1992). Lo spazio del teatro. Bari: Laterza.

---. (1987). "Il teatro e la festa." En: Cruciani, Fabrizio; Seragnoli, Daniele. II teatro italiano nel Rinascimento. Boloña: Il Mulino.

CRUCIANI, Fabrizio; SERAGNOLI, Daniele. (1987). II teatro italiano nel Rinascimento. Boloña: Il Mulino.

CHIAPPINI, Luciano. (1967). Gli Estensi. Varese: Dall' Oglio.

D’AMICO, Silvio. (1976). Storia del teatro. Milán: Garzanti.

D'ANCONA, Alessandro. (1891) Origini del teatro italiano (2 voll.). Turín: Loeschner.

DAVICO BONINO, Guido (editado por). (1977). II teatro italiano. Volumen II: La commedia del Cinquecento. (Tomo I). Turín: Einuadi.

DE LUCA, Antonio. (1975). "I prologhi delle commedie ariostesche." En: AA.VV., Atti del Convegno Internazionale Ludovico Ariosto. Roma: Accademia Nazionale dei Lincei.

DIONISOTTI, Carlo. (1967). Geografia e storia della letteratura italiana. Turín: Einaudi.

DE SANCTIS, Francesco. (1983). Storia della Letteratura Italiana (1870) Volumen I. Milán: Rizzoli.

DOGLIO, Federico. (1990). Storia del teatro. Il Cinquecento e il Seicento. Milán: Garzanti.

ELIAS, Norbert. (1994). El proceso de la civilización. Investigaciones sociogenéticas y psicogenéticas. México: F.C.E.. 
FERRONI, Giulio. (1980). Il testo e la scena. Saggi sul teatro del Cinquecento. Roma: Bulzoni Editore (Centro studi "Europa delle Corti" - Biblioteca del Cinquecento).

---. (1980). "La scena, I' autore, il signore nel teatro di corti padane." En: AA.VV. II teatro italiano del Rinascimento. Milán: Edizioni di Comunità.

FIRPO, Massimo, “Il Cardinale.” En Garin, Eugenio (compilador). L'uomo del Rinascimento. Op. Cit.

GRABHER, C. (1946). Sul teatro dell'Ariosto. Roma: Edizioni Italiane.

GUNDERSHEIMER, Werner L.. (1988). Ferrara estense. Lo stile del potere (1973). Modena: Edizioni Panini. ---. (1980). "Popular spectacle and the theater in Renaissance Ferrara." En AA.VV., II teatro italiano del Cinquecento. Milán: Edizioni di Comunità.

LANE, Frederic C.. (1978). Storia di Venezia (1973). Turín: Einaudi.

LOVARINI, Emilio. (1894). Antichi testi di letteratura pavana. Bolonia: Romagnoli.

LUCIANI, Gérard. (1995). "L'eco dei problemi del tempo nell'opera del Ruzante." En Angelo Beolco detto Ruzante. Padua: Edizioni Papergraf.

MURARO, Maria Teresa. (1986). "Le lieu des spectacles (publics ou privés) à Venise au Xve et au XVle siècles." (1963) En AA.VV., Le lieu théâtral à la Renaissance. Colloques Internationaux du Centre National de la Recherche Scientifique. (Compilado por Jean Jacquot). Paris: Éditions du Centre National de la Recherche Scientifique.

NICOLL, Allardyce. (1992). Lo spazio scenico. Storia dell'arte teatrale (1927). Roma: Bulzoni editore.

PIERI, Marzia. (1989). La nascita del teatro moderno in Italia tra XV e XVI secolo. Turín: Bollati Boringhieri.

RIPOSIO, Donatella. (1989). Nova Comedia v'appresento. Il prologo nella commedia del Cinquecento. Turín: Editrice Tirrenia Stampatori. 
SFORZA, Nora. (2001). “Angelo Beolco (Ruzante): la parábola de un intelectual contestatario”. En Burucúa, José Emilio, Corderos y elefantes. La sacralidad y la risa en la Modernidad clásica (siglos XV a XVII), MadridBuenos Aires: Miño y Dávila.

---. (2003). "'Si el sagrado Cardenal estima haberme comprado con sus regalos, no me es agrio o amargo devolvérselos y volver a mi libertad primera.' Ludovico Ariosto: un poeta-cortesano en busca de la libertad." En Bezián de Bousquets, Enriqueta (compiladora), Un acercamiento a la república de las letras (siglos XVI al XVIII). San Miguel de Tucumán: Facultad de Filosofía y Letras - Universidad Nacional de Tucumán.

STRONG, Roy. (1988). Arte y poder. Fiestas del Renacimiento 1450-1650 (1973). Madrid: Alianza.

VIOLA, Raffaello. (1949). Due saggi di letteratura pavana. Padua: Editoria Liviana.

WICKHAM, Glynne. (1988). Storia del teatro. Milán: II Mulino.

ZORZI, Ludovico; INNAMORATI, Giuliano; FERRONE, Siro. (1982). II teatro del Cinquecento. I luoghi, i testi e gli attori. Florencia: Sansoni Editore. 